Subscriber access provided by Caltech Library

\title{
Article
}

\section{Scanning electrochemical flow cell with online mass spectroscopy for accelerated screening of carbon dioxide reduction electrocatalysts}

\author{
Yungchieh Lai, Ryan J.R. Jones, Yu Wang, Lan Zhou, and John M. Gregoire
}

ACS Comb. Sci., Just Accepted Manuscript • DOI: 10.1021/acscombsci.9b00130 • Publication Date (Web): 16 Sep 2019

Downloaded from pubs.acs.org on September 17, 2019

\section{Just Accepted}

"Just Accepted" manuscripts have been peer-reviewed and accepted for publication. They are posted online prior to technical editing, formatting for publication and author proofing. The American Chemical Society provides "Just Accepted" as a service to the research community to expedite the dissemination of scientific material as soon as possible after acceptance. "Just Accepted" manuscripts appear in full in PDF format accompanied by an HTML abstract. "Just Accepted" manuscripts have been fully peer reviewed, but should not be considered the official version of record. They are citable by the Digital Object Identifier (DOI®). "Just Accepted" is an optional service offered to authors. Therefore, the "Just Accepted" Web site may not include all articles that will be published in the journal. After a manuscript is technically edited and formatted, it will be removed from the "Just Accepted" Web site and published as an ASAP article. Note that technical editing may introduce minor changes to the manuscript text and/or graphics which could affect content, and all legal disclaimers and ethical guidelines that apply to the journal pertain. ACS cannot be held responsible for errors or consequences arising from the use of information contained in these "Just Accepted" manuscripts. 


\title{
Scanning electrochemical flow cell with online mass spectroscopy for accelerated screening of carbon dioxide reduction electrocatalysts
}

\author{
Yungchieh Lai ${ }^{1}$, Ryan J.R. Jones ${ }^{1}$, Yu Wang ${ }^{1}$, Lan Zhou ${ }^{1}$, and John M. Gregoire ${ }^{1,2^{*}}$ \\ ${ }^{1}$ Joint Center for Artificial Photosynthesis, California Institute of Technology, Pasadena, CA 91125 \\ ${ }^{2}$ Division of Engineering and Applied Science, California Institute of Technology, Pasadena, CA 91125 \\ *gregoire@caltech.edu
}

\begin{abstract}
:
Electrochemical conversion of carbon dioxide into valuable chemicals or fuels is an increasingly important strategy for achieving carbon neutral technologies. The lack of a sufficiently active and selective electrocatalyst, particularly for synthesizing highly reduced products, motivates accelerated screening to evaluate new catalyst spaces. Traditional techniques, which couple electrocatalyst operation with analytical techniques to measure product distributions, enable screening throughput at 1-10 catalysts per day. In this paper, a combinatorial screening instrument is designed for MS detection of hydrogen, methane, and ethylene in quasi-real time during catalyst operation experiments in an electrochemical flow cell. Coupled with experiment modelling, product detection during cyclic voltammetry (CV) enables modelling of the voltage-dependent partial current density for each detected product. We demonstrate the technique by using the well-established thin film $\mathrm{Cu}$ catalysts and by screening a $\mathrm{Pd}-\mathrm{Zn}$ composition library in carbonate-buffered aqueous electrolyte. The rapid product distribution characterization over a large range of overpotential makes the instrument uniquely suited for accelerating screening of electrocatalysts for the carbon dioxide reduction reaction.
\end{abstract}

\section{Introduction:}

The prospect of utilizing solar energy to promote the electrochemical or photoelectrochemical reduction of $\mathrm{CO}_{2}$ to transportation fuels has motivated extensive research aimed at identifying highly active and selective electrocatalysts for the $\mathrm{CO}_{2}$ reduction reaction $\left(\mathrm{CO}_{2} \mathrm{RR}\right){ }^{1,2}$ Unfortunately, many of the electrocatalyst materials investigated to date predominately produce $2 \mathrm{e}^{-}$products such as $\mathrm{CO}$ and formate and/or catalyze the competing hydrogen evolution reaction (HER). ${ }^{3}$ These products are not as readily used as fuels as are hydrocarbons or alcohols. To date, only $\mathrm{Cu}$-based catalysts have been to reduce $\mathrm{CO}_{2}$ to hydrocarbons and alcohols with appreciable Faradaic efficiency (FE), yet these catalysts suffer from poor selectivity to any single product and from high overpotentials for generating the highly reduced products. ${ }^{3,4}$ Exploration of other electrocatalysts has been limited to date, in part due to the limited throughput of electrocatalyst screening platforms that couple with analytical techniques to measure product distributions. Since product distributions vary with catalyst overpotential, ${ }^{4}$ the search for additional catalysts is best performed by screening over a range of overpotentials for each candidate catalyst, further limiting throughput. Since the detection of even small quantities of desired products could open new lines of inquiry, low detectability limits are also desirable, creating further challenges for increasing experiment throughput. Motivated by these considerations, we designed a screening platform intended to maximize catalyst screening throughput while scanning over ca. $1 \mathrm{~V}$ range of overpotential with ca. $0.03 \mathrm{~mA} / \mathrm{cm}^{2}$ (geometric area) partial current density detection limit for desirable light hydrocarbons $\left(\mathrm{CH}_{4}\right.$ and $\left.\mathrm{C}_{2} \mathrm{H}_{4}\right)$, which for catalyst operating above $1 \mathrm{~mA} / \mathrm{cm}^{2}$ corresponds to $\mathrm{FE}$ 
detectability better than $3 \%$. The undesired product from the competing HER reaction $\left(\mathrm{H}_{2}\right)$ is also detected to assess the overall FE for the $\mathrm{CO}_{2} \mathrm{RR}$. These goals were met through design of a flow cell reactor, pervaporator with differential water pumping, and mass spectroscopy-based detection system that provide product analysis at $12 \mathrm{~s}$ intervals during electrochemical experiments. Coupled with experiment modelling, product detection during cyclic voltammetry $(\mathrm{CV})$ enables estimation of the voltage-dependent partial current density for each detected product. This combination of a scanning electrochemical flow cell with online mass spectroscopy contributes to the broader field of combinatorial electrochemistry ${ }^{5}$ and enables new screening modalities compared to other combinatorial screening approaches, in particular due to the rapid throughput obtained at the expense of the breadth of detected reaction products. ${ }^{6-9}$

The use of mass spectroscopy coupled to electrocatalysis has been well demonstrated with differential electrochemical mass spectrometry (DEMS), an analytical technique that introduces the inlet to a mass spectrometer into an electrochemical reactor. ${ }^{10,11,12}$ It has been widely utilized to provide quasireal-time detection of electrochemical reactants/products/intermediates. The DEMS technique was first demonstrated ${ }^{13}$ using a cell in which electrode material is deposited directly onto the PTFE membrane inlet to the mass spectrometer. Its major advantage is quick instrument response time and high reaction product collection efficiency. However, when the reactant(s) of the desired reaction are volatile, as is the case for $\mathrm{CO}_{2}$ in the $\mathrm{CO}_{2} \mathrm{RR}$, reactant volatilization lowers its concentration at the electrode surface, changing the electrochemical environment compared to a traditional experiment. ${ }^{10}$ The intensive preparation of the working electrode with membrane also limits opportunities to deploy the technique for high throughput studies.

Thin-layer-type DEMS cells were developed in the $1990 \mathrm{~s}^{14}$ to investigate a wider variety of electrode types. In contrast to the classic cells, the working electrode of a thin layers DEMS cell is separated from the membrane interface via a thin-layer of electrolyte, eliminating the need to prepare membrane electrodes. Dual thin layer flow cells, where WE and membrane interfaces are segregated in two separate thin-layer compartments, were later introduced to help decouple reactor operation with product detection. ${ }^{15}$ However, electrochemical engineering challenges remain, particularly with the tip of the DEMS probe influencing mass transport at the working electrode surface, and further introducing variable resistance between the working electrode and the reference electrode.

Online electrochemical mass spectrometer (OLEMS) was later introduced to avoid complicated cell configurations while retaining the ability to study a variety of electrode formats. The defining feature of OLEMS is the MS inlet which consists of a capillary tip covered ${ }^{16}$ with a PTFE membrane. ${ }^{17}$ The small tip inlet is placed near the working electrode $(10-50 \mu \mathrm{m})$ to implement direct sampling of the reaction surface. The use of a capillary inlet was further employed to create a multi-electrode scanning DEMS (SDEMS) cell for investigating electrode arrays/libraries of different types and compositions. ${ }^{8,9,18}$ In such applications, the capillary inlet is attached to a positioning system to raster along an electrode or array of catalysts on a common WE. Such a strategy creates a tradeoff between using a small WE-capillary distance for spatial resolution and product sampling and using a larger distance to avoid disruption of the local mass transport. Similar tradeoffs exist with the small product sampling area compared to WE area that can limit the ability to establish FE values.

Scanning electrochemical flow-cells provide consistent and desirable mass transport conditions, motivating their development for characterization of both discrete ${ }^{19}$ and continuous ${ }^{7}$ composition libraries. Klemm et al. ${ }^{20}$ studied corrosion processes by characterizing material dissolution via a scanning flow cell (SFC) coupled to ICP-MS, enabling a throughput of ca. $10^{2}$ samples per day. Their SFC was later coupled to an OLEMS for characterization of volatile reaction products. ${ }^{7,21}$ This approach provided semi-quantitative evaluation of the electrochemical production rate of hydrogen and some $\mathrm{CO}_{2} \mathrm{RR}$ 
products, enabling comparison of the relative production rates of the catalysts they investigated. More recently, Katsounaros et al. reconfigure the SFC-MS design and coupled with a nebulizer to expand detection of a broad range of product including organic acids in real-time. ${ }^{22}$ Such development helps quick and complete assessment of potentially formed product distribution over a catalyst. However, the concerns with a local sensing probe remain. ${ }^{21}$ To provide product detection over an entire WE, Clark et al. ${ }^{23}$ introduced a DEMS flow cell that provides excellent characterization of individual electrocatalysts, motivating use of a similar design for product sampling in the present work in which we could combine this type of pervaporation cell with a combinatorial electrochemical flow cell.

While displacing the pervaporation cell from the electrochemical cell enables product sampling from the electrolyte effluent to facilitate integration of the electrochemical and MS data, the associated dilution of products compared to their high concentration within microns of the WE surface poses substantial challenges for obtaining the desired sensitivity. Direct connection of a PTFE pervaporator to the MS inlet introduces a large water flux that is traditionally pumped primarily by a mechanical pump with a small fraction of the gas stream entering the MS inlet due to the limited pumping speed of the MS system at the high vacuum levels required for MS operation. The ratio of molar pumping rate between the MS and mechanical pump proportionally lowers product detection, and the large concentration of water in the MS additionally raises the background level of the spectrometer. ${ }^{21,23}$ In this work, we present an electrochemical mass spectrometry (EC-MS) instrument that circumvents these issues while sampling the bulk electrolyte, and additionally demonstrate the role of simulation-based interpretation of experimental results to realize the on-line detection of $\mathrm{H}_{2}, \mathrm{CH}_{4}$ and $\mathrm{C}_{2} \mathrm{H}_{4}$ during $\mathrm{CV}$ at $0.01 \mathrm{~V} / \mathrm{s}$. We demonstrate the system by using the well-established thin film $\mathrm{Cu}$ catalysts and screening a Pd-Zn library in carbonatebuffered aqueous electrolyte and show a fast and reproducible result of reaction product quantification.

\section{Experimental Section:}

\section{Electrochemical-Mass Spectrometry (EC-MS)}

The EC-MS design is shown in Figure 1. The electrochemical flow cell is isolated from the product collection chamber (pervaporation chamber) to facilitate a well-defined electrochemical reaction environment. Gaseous reaction products formed at the catalyst surface remain dissolved in the electrolyte, which is continuously transported to a pervaporation chamber via peristaltic pump located downstream of this chamber. Figure S1 shows higher electrolyte flow rate results in more stable (less noises) MS response due to fewer bubbles formed and faster MS baseline recovery. In contrast, it also dilutes the reaction product and hence lower MS response intensity. By balancing these effects, the electrolyte flow rate was selected to be $160 \mathrm{uL} / \mathrm{s}$. In the pervaporation chamber, the product-containing electrolyte stream flows over a porous membrane (PTFE, $20 \mathrm{~nm}$ pore size, Hangzhou Cobetter Filtration Equipment Co.) that is exposed on one side to a high vacuum system. This allows volatile electrolyte species, including reaction products as well as water vapor, to be continuously introduced to the vacuum system. A custom in-line desiccant chamber is inserted between the pervaporation chamber and the MS to remove the water vapor, performing the traditional role of the mechanical pump to lower the vacuum line pressure to a level suitable for the MS with the critical additional feature that the water vapor and alcohols are specifically pumped, substantially increasing the concentration of the gas products to be detected. This method of invacuum water and alcohol pumping improves the detection limit of reaction gas products by a factor of ca. 100 (see Figure 2). The stainless steel desiccant chamber is constructed of tubing and vacuum connectors. The chamber is ca. $62 \mathrm{~cm}$ long with internal diameter $0.81 \mathrm{~cm}$. The chamber is filled with molecular sieve type 3A (Sigma Aldrich) particles of diameter 2.5 to $3.5 \mathrm{~mm}$, enabling ca. $20 \mathrm{~g}$ of 
desiccant that supports ca. 5 hours of operation before desiccant saturation requires regeneration, for example by heating the chamber in a vacuum tube furnace at $250{ }^{\circ} \mathrm{C}$ for 10 hours. The desiccant chamber is connected to the pervaporator and to MS by $1 / 16$ in. tubing.

The electrochemical flow cell (Figure 1) is machined from Polyether ether ketone (PEEK) material for chemical inertness and allows for three-electrode electrochemistry to be performed on planar electrodes where the active area is defined by the $6.4 \mathrm{~mm}$ inner diameter of the Buna-N O-ring that seals the cell to the electrode. Prior to daily experiment, the cell was treated with UV-generated ozone to reduce the wetting angle of the electrolyte on the exposed surfaces of the cell, which reduces the holdup of gaseous product bubbles. ${ }^{23} \mathrm{~A}$ spring-loaded mount of the flow cell enables sealing with fixed force via stepper motor-controlled elevation of the working electrode, and additional stepper motors (Dover Motion) enable lateral translation when the plate is disengaged from the cell. Note that electrolyte flow is stopped during cell disengagement, travel, and engagement, and the cell can be flushed with gas to avoid electrolyte spill. Since the membrane in the pervaporator is exposed to gas during translation and commencement of electrolyte flow, a valve between the pervaporator and molecular sieve chamber is closed until electrolyte flow has started and the system is ready to start measurements. Combined with control software, the system performs automated serial experimentation of an array of catalysts on an electrode plate. The electrochemical flow cell also contains an additional port for auxiliary instrumentation, such as a fiber optic for introducing front-side illumination to the electrode, but is not utilized in the present study.

Electrolysis was carried out with a Gamry Reference 600TM potentiostat. All electrochemical data were collected using a $\mathrm{Ag} / \mathrm{AgCl}$ reference electrode (LF2, Innovative Instruments) and converted to a reversible hydrogen electrode (RHE) scale using the measured solution $\mathrm{pH}$ of 6.8 The uncompensated solution resistance was measured by performing electrochemical impedance spectroscopy (EIS) in the frequency range of $100 \mathrm{~Hz}-500 \mathrm{kHz}$ with an amplitude of $10 \mathrm{mV}$ at the open circuit potential of a $\mathrm{Cu}-\mathrm{Pt}$ working electrode-counter electrode system. The uncompensated resistance, $\mathrm{R}_{\mathrm{u}}$, was measured by using a Nyquist plot of the EIS spectra and was found to be $60 \Omega$. All electrochemical measurements are compensated by this value in post-processing to yield figures with resistance-compensated values of electrochemical potential. Prior to the electrolysis, the electrolyte $\left(0.1 \mathrm{M} \mathrm{KHCO}_{3},>=99.95 \%\right.$ trace metals basis, Sigma Aldrich) was purged with $\mathrm{CO}_{2}(99.999 \%$, Airgas) for at least $30 \mathrm{~min}$. A bipolar membrane (BPM, Fumasep ${ }^{\circledR}$ FBM single film, Fumatech) was used to separate the working and counter electrodes. Platinum wire (99.9\%, Sigma Aldrich) which is accommodated in the middle green tube (in figure 1) was used as the counter electrode. The $\mathrm{CE}$ chamber is recirculated with the same electrolyte bubbled with $\mathrm{CO}_{2}$ as used for WE through the two green tubes shown in figure 1 (left: in; right: out). The surface area of the counter electrode was ca. $0.25 \mathrm{~cm}^{2}$, while the working electrode surface area was $0.32 \mathrm{~cm}^{2}$.

Mass spectra were acquired on a Hiden HPR20 mass spectrometer connected to the outlet of the molecular sieve chamber. An electron energy of $70 \mathrm{eV}$ was used for ionization of all species, with an emission current of $20 \mu \mathrm{A}$. Hydrogen $(\mathrm{m} / \mathrm{z}=2)$, methane $(\mathrm{m} / \mathrm{z}=15)$, ethylene $(\mathrm{m} / \mathrm{z}=26)$ ions were accelerated with a voltage of $3 \mathrm{~V}$. All mass-selected product cations were detected by a secondary electron multiplier with a detector voltage of $940 \mathrm{~V}$. The dwell and settle time were set at $25 \%$ to optimize for speed and a data point was recorded every ca. $12.5 \mathrm{~s}$.

\section{Catalyst Synthesis}

To demonstrate the operation of the high-throughput analytical electrochemistry system, $\mathrm{Cu}$ thin film electrocatalysts were fabricated using DC magnetron sputtering of a 2" Cu metal target at $50 \mathrm{~W}$ in 6 mTorr Ar onto a $100 \mathrm{~mm}$-diameter $\mathrm{Si}$ wafer with an approximately $170 \mathrm{~nm} \mathrm{SiO}{ }_{2}$ diffusion barrier, using a 
previously described sputter system with $10^{-5} \mathrm{~Pa}$ base pressure. ${ }^{24}$ After deposition, the films were stored in a nitrogen purge box until the day of electrochemical testing, although no other catalyst treatment was performed prior to electrocatalyst screening. The Pd-Zn thin film electrodes were deposited under similar conditions from elemental metal targets with Pd and $\mathrm{Zn}$ sources at $24 \mathrm{~W}$ and $36 \mathrm{~W}$, respectively. The separation of the source provided a continuous composition gradient across the Si wafer enabling catalyst testing of 7 electrodes from $\mathrm{Pd}_{0.68} \mathrm{Zn}_{0.32}$ to $\mathrm{Pd}_{0.04} \mathrm{Zn}_{0.96}$, with the composition variation within each $5 \mathrm{~mm}$ daimeter electrode being less than $4 \%$, sufficiently small to approximate a uniform metal catalyst. The deposited thin film library was annealed in $5 \% \mathrm{H}_{2} / \mathrm{Ar}$ at $350^{\circ} \mathrm{C}$ for 60 minutes in a tube furnace.

\section{Catalyst Characterization}

The composition and structure of the Pd-Zn catalysts were characterized via $\mathrm{X}$-ray fluorescence (XRF, EDAX Orbis MicroXRF) and synchrotron x-ray diffraction (XRD). The synchrotron measurements were performed at beamline 1-5 of the Stanford Synchrotron Radiation Light source (SSRL) at SLAC National Accelerator Laboratory using a $12.7 \mathrm{keV}$ source in reflection scattering geometry with a setup described previously. ${ }^{25}$ Phase identification proceeded by identifying candidates in the International Crystallography Diffraction Database (ICDD $\left.{ }^{\circledR}\right)$ that best match the integrated 1D XRD patterns.

\section{Simulator for Data Modelling}

For a given volatile species, the measured MS signal is related to the concentration of the species in the flowing electrolyte from the electrochemical flow cell to the pervaporation cell. The porous PTFE membrane creates channels of relatively static electrolyte through which species must diffuse to enter the vacuum system and MS inlet. Understanding time-varying MS measurements requires a model for the diffusion through the membrane pores. The various parameters and variable relating the electrochemical generation of volatile molecules to their MS detection are detailed in Table 1 and used in the Fickian diffusion model with the concentration of each species (M) in the membrane governed by

$$
\frac{d C_{M}}{d t}=\frac{d\left(D_{M} \frac{d C_{M}}{d x}\right)}{d x} .
$$

Given the values for the electrolyte concentration $\left(\mathrm{C}_{M}\right)$ as a function of time, numerical evaluation of this differential equation enables calculation of the concentration profile through the thickness of the membrane and thus the molecular flow rate into the vacuum system $\left(\Gamma_{M}\right)$ that is proportional to the partial pressure in the MS $\left(\mathrm{P}_{\mathrm{M}}\right)$.

Parameters for the numerical evaluation include the time step $\left(\delta_{t}\right)$ and length step inside membrane $\left(\delta_{\mathrm{x}}\right)$, which are empirically chosen to be sufficiently small that the simulator results are stable. The effective electrolyte channel length through the membrane $\left(\mathrm{X}_{\mathrm{mem}}\right)$, electrolyte diffusion layer at the membrane-flowing electrolyte interface $\left(\mathrm{d}_{\text {mem }}\right)$, and mass spec transfer coefficient $(\rho)$ are estimated from known properties of the system and tuned as necessary to match calibration data discussed below. The parameter $\rho$ is the ratio of 2 molecule-specific quantities $\left(\mathrm{P}_{\mathrm{M}} / \mathrm{C}_{\mathrm{M}}\right)$ but is itself not molecule-specific under the assumption that all volatile molecules will evaporate and be pumped through the vacuum system with effective time constants far faster than that of the diffusion within the membrane; i.e. that compared to the ca. $10 \mathrm{~s}$ time scale of diffusion and MS measurements, the change to the gas composition in the MS system due to any change to molecular concentrations at the membrane-vacuum interface occurs effectively instantaneously. This calibration constant encompasses the ratio of the evaporation rate and 
the pumping rate and the differential pumping fraction of the MS for species not sorbed in the desiccant chamber (ca. 10\%).

Molecule-specific parameters used in the simulator that are determined via calibration measurements include the diffusion coefficient of molecules in electrolyte $\left(D_{M}\right)$, which are confirmed to be within the range of published values for aqueous solutions, and the relative sensitivity of each gas molecule in MS $\left(\mathrm{S}_{\mathrm{M}}\right)$. Calibration of all necessary parameters proceeded by matching the modeled MS signals $\left(\mathrm{P}_{\mathrm{M}}\right)$ with experimental data acquired using electrolyte flow with toggling from product-free electrolyte to electrolyte saturated with calibration gas, corresponding to $\mathrm{C}_{\mathrm{M}}$ values of $3.88 \mathrm{mM} \mathrm{H}_{2}, 6.88$ $\mathrm{mM} \mathrm{CH}_{4}$, and $23 \mathrm{mM} \mathrm{C}_{2} \mathrm{H}_{4}$. The duration of flow of the calibration electrolyte was $24,38,120$, and $600 \mathrm{~s}$ in subsequent measurements to mimic constant production rates of those molecules for the respective duration. By inputting the corresponding square-wave profiles of $\mathrm{C}_{\mathrm{M}}$ into the model, we confirmed that the model replicates the MS signals over these different time scales, as shown in Figure 3. The final parameters selected are noted in Table 1 . Since the model provides the molecular flow rates $\left(\Gamma_{M}\right)$, we confirmed that the total flow rate of order $10^{-13} \mathrm{~mol} / \mathrm{s}$ matches our expectation from the manufacturer's turbo pump rate, as expected by conservation of molecules. One example calibration simulation is shown in Figure 4 including the concentration profile through the thickness of the membrane at various snapshots in time.

With the model parameters in place, any $\mathrm{C}_{\mathrm{M}}(\mathrm{t})$ profile can be input into the model to produce the corresponding $\mathrm{P}_{M}(t)$, and comparison with MS measurements determines whether the $C_{M}(t)$ profile is consistent with experiment. It is worth noting that the model is always run to predict $P_{M}$ from $C_{M}$ and not vice versa because it is not readily invertible. Candidate $C_{M}(t)$ profiles are generated for a given electrochemical experiment, which for the present work includes electrolyte flow at $160 \mu \mathrm{L} / \mathrm{s}$ and a CV at scanning rate $10 \mathrm{mV} / \mathrm{s}$ from $\mathrm{E}_{0}$ (i.e. starting potential) to $\mathrm{E}_{1}$ and back. At any point in the $\mathrm{CV}$, each product is being created at a partial current density $\mathrm{J}_{\mathrm{p}, \mathrm{M}}$, which from the $\mathrm{e} / \mathrm{mol}$ and flow rate corresponds to concentration of

$$
\mathrm{C}_{\mathrm{M}}=\mathrm{J}_{\mathrm{p}, \mathrm{M}} /\left(\mathrm{fF} \mathrm{n}_{\mathrm{M}}\right)
$$

assuming the flow is sufficiently high to keep all concentrations below solubility limits, an assumption that is only violated at high current densities discussed below. The measured $\mathrm{P}_{\mathrm{M}}$ are proportional to $\mathrm{J}_{\mathrm{p}, \mathrm{M}}$ so creating a family of all possible MS measurements up to this proportionality constant requires assemble of a set of possible $\mathrm{J}_{\mathrm{p}, \mathrm{M}}$ profiles. By simulating each $\mathrm{J}_{\mathrm{p}, \mathrm{M}}$ profile, a library of candidate $\mathrm{P}_{\text {model,M }}$ are obtained, and then data analysis for the $\mathrm{P}_{\text {meas, }}$ from each CV experiment proceeds by calculating the fit loss for each candidate $\mathrm{P}_{\text {model, } \mathrm{M}}$ through regression fitting of the single proportionality constant parameter and then choosing the $\mathrm{P}_{\text {model, } \mathrm{M}}$ profile with minimum loss.

While a broad range of possible $\mathrm{J}_{\mathrm{p}, \mathrm{M}}$ profiles can be conceived, for the purposes of the present work we assume the variation with $\mathrm{E}$ is the same on the cathodic and anodic portions of the $\mathrm{CV}$. The variation of $J_{p, M}$ as a function of $E$ is generally smooth, especially during a linear voltage sweep, with typical models including exponential (e.g. Butler-Volmer process), sigmoidal (e.g. mass-transport-limited process), or localized peak (e.g. when competing reactions create a more complicated thermodynamic and kinetic landscape that produces an optimal potential for production of a given product). Any of these shapes can be approximated by a Gaussian provided consideration of a sufficiently broad range of the center-potential and width parameters, especially if the center potential is allowed to go beyond the range of the CV such that only the exponential tail of the Gaussian function is utilized within the CV potential 
range. Under this Gaussian model the partial current density for generation of a given molecular species is described by

$$
J_{p, M}\left(E, \sigma_{M}, \mu_{M}, J_{1, M}\right)=J_{1, M} * \alpha * \frac{e^{\left(-\left(E-\mu_{M}\right)^{2}\right)}}{2 * \sigma_{M}^{2}}, \alpha=\frac{2 * \sigma_{M}^{2}}{e^{\left(-\left(E 1-\mu_{M}\right)^{2}\right)^{2}}},
$$

and using the time-dependent potential of the $\mathrm{CV}$, the time profile of $\mathrm{J}_{\mathrm{p}, \mathrm{M}}$ is obtained. $\mathrm{J}_{1, \mathrm{M}}$ is the partial current density at $E_{1}$ and serves as the scaling factor for the loss minimization for a given $\sigma_{M}, \mu_{M}$. As noted above, flexibility in the profiles is obtained by varying $\mu_{\mathrm{M}}$ beyond the $\mathrm{CV}$ potential range, motivating the constraint that $\mu_{\mathrm{M}} \geq \mathrm{E}_{1}-2 * \sigma_{\mathrm{M}}$ to avoid inclusion of Gaussian models that are only activated at the "tail" of the distribution.

To provide one example of a more complicated family of candidate profiles, consider hysteresis in $\mathrm{J}_{\mathrm{p}, \mathrm{M}}$ between the cathodic and anodic sweeps requiring independent $\sigma_{\mathrm{M}}$ and $\mu_{\mathrm{M}}$ for the cathodic sweep and for the anodic sweep. Continuity at the turn-around potential is obtained by using a single value for $\mathrm{J}_{1, \mathrm{M}}$, and then the same data processing proceeds by choosing a set of values for the cathodic and anodic $\sigma_{\mathrm{M}}$ and $\mu_{\mathrm{M}}$.

The final aspect of the data processing routine is the design of a loss function for the $\mathrm{J}_{1, \mathrm{M}}$ regression, for which we use a modified least-squares approach. Due to occasional bubble nucleation in the electrolyte, which occurs with regularity when the total current density exceeds ca. $5 \mathrm{~mA} / \mathrm{cm}^{2}$, spikes in $\mathrm{P}_{\text {meas, } \mathrm{M}}$ can occur that are not modelled in $\mathrm{P}_{\text {model, }}$, motivating lowered sensitivity to positive residuals through relative weighting of negative residuals by a factor of 5 . The most important aspect of the measurement is the onset of product formation during the cathodic sweep, motivating an additional weighting of residuals from measurements in the first half of the CV by an additional factor of 3 . Even with this custom loss function, we have observed that large outliers can result in loss minimization with very small values of $\sigma_{\mathrm{M}}$, which can result in an unphysical $\mathrm{FE}$ value for a small region of the $\mathrm{CV}$ and near zero $\mathrm{FE}_{\mathrm{M}}$ for the rest of the CV. To avoid such unphysical solutions, the regression is performed with an upper limit on $\mathrm{J}_{1, \mathrm{M}}$ corresponding to the value that would lead to $\mathrm{FE}_{\mathrm{M}}$ of $110 \%$, which is calculated from the total current $\mathrm{J}$ for the respective $\mathrm{CV}$ experiment.

Since spikes in the electrochemical current can result in unphysical spikes in $\mathrm{FE}_{\mathrm{M}}, \mathrm{J}$ is smoothed using cubic Savitsky-Golay filter with a window of 129 data points corresponding to $129 \mathrm{mV}$. This filtering is not applied to the first 64 data points since the transient capacitive current at the onset of the CV is not smooth on this scale. To avoid division by zero and negative $\mathrm{FE}$ values, only values of $\mathrm{J}$ below $-0.01 \mathrm{~mA}$ are considered in FE calculations.

\section{Results and Discussion:}

Cyclic voltammetry was conducted at $10 \mathrm{mV} / \mathrm{s}$ to demonstrate the ability of the EC-MS to rapidly quantify the generation rates of multiple electrochemical reaction products in real time. Six separate samples from a single $\mathrm{Cu}$ film were tested to examine the reproducibility in a standard serial screening across a combinatorial library. Polycrystalline $\mathrm{Cu}$ was selected for validating the system because its product distribution is well documented in the literature and includes all products that can be detected as well as others that cannot be detected by our system. The recorded MS signal and modeled electrochemical results of the 6 testes are shown in Figure 5, demonstrating that the modeled MS signal generally matches well with the measured data points with a few outliers due to bubbles, as described above. Figures 6 and 7 show the modeled currents and their corresponding FE with sufficient consistency 
among the 6 experiments to demonstrate that any substantial variation in FE profiles over a combinatorial library could be identified, particularly for the last $2 \mathrm{CV}$ cycles. The $3 \mathrm{CV}$ cycles commenced on the $\mathrm{Cu}$ thin films without any pretreatment, so the relatively varied results in the first cycle can be attributed to variation in organic or other contaminants that appear to be removed in subsequent $\mathrm{CV}$ cycles.

The onset potentials for the different reactions, i.e. where FE first exceeds $1 \%$, are a descriptor of electrocatalytic performance for generation of the respective products. The values of ca. -0.7 to $-0.8 \mathrm{~V}$ vs. RHE for $\mathrm{C}_{2} \mathrm{H}_{4}$ and ca. -0.9 to $-1 \mathrm{~V}$ vs. $\mathrm{RHE}$ for $\mathrm{CH}_{4}$, along with the values of $\mathrm{Jp}$ and FE shown in Figure 6 and 7 , are in excellent agreement with reported values from traditional long-duration chronoamperometry experiments. ${ }^{4}$ The total $\mathrm{FE}$ for $\mathrm{CO}$ and liquid products not detected by our high throughput instrument is also in good agreement with the sub-100\% FE in Figure 7, which from a catalyst screening perspective means that we can successfully identify when we are "missing" products that need to be detected in subsequent experiments such as the lower throughput screening system we reported previously. ${ }^{6}$

The importance of the diffusion modelling described above highlighted by the rapid changes in partial current density compared to the time response of the detection system due to the high CV scan rate. To characterize catalysts without the need for simulation, Clark et al. ${ }^{23}$ utilized a cathodic voltage sweep at $0.2 \mathrm{mV} / \mathrm{s}$. In the present work, the simulation-based data processing uses the measurements from the entire $\mathrm{CV}$ to provide smooth models for $\mathrm{Jp}_{\mathrm{M}}$ and $\mathrm{FE}_{\mathrm{M}}$ while maintaining a much higher scan rate of .e. $10 \mathrm{mV} / \mathrm{s}$ so that each catalyst can be evaluated using $3 \mathrm{CV}$ cycles at a throughput of $540 \mathrm{~s}$ per sample. This high speed scanning was not achieved at a cost of sacrificing measurement accuracy. The obtained partial current density for our reported gas product (Figure 6) generally agrees well with that reported by Clark et $\mathrm{al}^{23}$ at similar potentials. Moreover, due to separating electrochemical cell from product collection chamber (pervaporator cell), this system allows to test any type of plate electrode with area $>$ $0.32 \mathrm{~cm}^{2}$ without strict restrictions for catalysts preparation. Accompanied with the design for simple changes of measurement locations, in contrast to the DEMS setup by Clark et al., EC-MS can quickly filter out catalysts with no interests and find out promising ones for further detailed research.

Due to gradual variation in the MS sensitivity, we have found that a daily calibration of the sensitivity factors is important establishing correct absolute values of $\mathrm{Jp}_{\mathrm{M}}$ and $\mathrm{FE}_{\mathrm{M}}$. Figure 8 shows results for $\mathrm{Cu}$ thin film electrodes tested on different days over a span of 4 months, revealing excellent repeatability after the initial CV. In Figures 6, 7 and 8, the most notable variation in $\mathrm{Jp}_{\mathrm{M}}$ and $\mathrm{FE}_{\mathrm{M}}$ is for $\mathrm{H}_{2}$ between -0.4 and $-0.8 \mathrm{~V}$ vs RHE. At the highest potentials, the low value of $\mathrm{J}$ makes the value of $\mathrm{FE}_{\mathrm{M}}$ less well determined, but we believe that the more substantial cause of this variation is that the $J p_{M}$ profile is not sufficiently modelled by the Gaussian profile assumed in the model, which is consistent with the reported potential-dependent $\mathrm{FE}$ of $\mathrm{H}_{2}$. The high MS signals at low applied potential dominate the loss function, making this region of the $\mathrm{FE}_{\mathrm{M}}$ results well reproduced in the various experiments. Since the Jp at high potential is not well explained by the model, the best-fit model is more susceptible to noise, creating the noted variability in $\mathrm{Jp}_{\mathrm{M}}$ and $\mathrm{FE}_{\mathrm{M}}$. While more complex models could be applied to better model the $\mathrm{H}_{2}$, such additional effort is not well motivated by the research goals. For catalyst discovery, the hydrocarbons comprise the desirable products, making their reproducible detection and characterization of utmost importance. The absence of $\mathrm{H}_{2}$ would be a positive result and the noted variability in low-overpotential $\mathrm{FE}_{\mathrm{M}}$ would not be an issue in that case. The larger lesson is that trade-offs exist for an accelerated screening technique, and before embarking on high throughput campaigns one must validate that the signals of greatest interest can be robustly characterized. The present work demonstrates the ability of this new screening system to identify hydrocarbon forming and/or HER- 
inactive catalysts, and the same hardware and simulation-based analysis approach can be tailored for other screening activities with appropriate modification of experimental parameters.

The same screening technique was applied to a series of thin film electrocatalysis in the binary Pd-Zn library. Pd-Zn was selected because the two elements and several related catalysts have been reported for electrochemical $\mathrm{CO}_{2} \mathrm{RR}$, and the binary phase diagram contains several intermallic compounds that may exhibit unique electrocatalytic activity. Previous experimental work in related systems includes $\mathrm{Pd}^{3}$ and Pd-based bimetallic electrocatalysts $\mathrm{Pd}-\mathrm{Cu},{ }^{26} \mathrm{Pd}-\mathrm{Au},{ }^{27} \mathrm{Pd}-\mathrm{Pt},{ }^{28} \mathrm{Pd}-\mathrm{Sn},{ }^{29} \mathrm{Pd}-$ $\mathrm{Ru}^{30}$ and $\mathrm{Pd}-\mathrm{Te},{ }^{31}$ which have all been shown to form $\mathrm{CO}$ and formate. ${ }^{32} \mathrm{Zn}$ was also reported for $\mathrm{CO}$ formation but the reported numbers of FE vary significantly, ${ }^{3,33}$ likely due to variation in the oxidation state of Zn catalysts. ${ }^{33}$

The $[2,0,1]$ surface of tetragonal PdZn phase was identified by Tran and Ulissi ${ }^{34}$ as having a desirable CO binding energy. XRD characterization of the Pd-Zn library (Fig. 9) confirm formation of this target phase, although demonstration of presence or absence of the target facet is beyond the scope of the present work. The XRD analysis also reveals the presence of a $\mathrm{Pd}_{2.35} \mathrm{Zn}_{10.65}$ intermetallic phase in the $\mathrm{Zn}$-rich compositions as well as a $\mathrm{Zn}$-alloyed fcc-Pd phase for Pd-rich compositions.

The electrochemical-analytical characterization of $7 \mathrm{Pd}-\mathrm{Zn}$ catalysts is shown in Figure 10. No formation of methane and ethylene were observed, with hydrogen being the only product detected by our instrument, in agreement with previous reports on $\mathrm{Pd}$ and $\mathrm{Zn}$-based catalysts noted above. A FE for $\mathrm{H}_{2}$ well below $100 \%$ indicates that undetected products are being formed, which given the related catalysts discussed above is likely formate and/or CO. The Pd-rich compositions appear to have a high FE for these $2 \mathrm{e}^{-} \mathrm{CO}_{2} \mathrm{RR}$ products, in agreement with previous studies. The FE for $\mathrm{H}_{2}$ and the total catalytic current increases with $\mathrm{Zn}$ concentration, with the most Zn-rich catalysts exhibiting current densities that well exceed the ca. $5 \mathrm{~mA} / \mathrm{cm}^{2}$ limit to avoid bubble nucleation. Some instability in the resulting electrochemical measurement is evident in Figure 10, and from a screening perspective demonstrates that these catalysts are far too active for HER to be further considered for $\mathrm{CO}_{2} \mathrm{RR}$.

The development of an effective high throughput experiment involves concomitant integration of mutually compatible components. The high electrolyte flow rate use in this work was chosen to mitigate gaseous segregation of reaction products and also provides an electrochemical environment that is less sensitive to catalyst morphology than that of a static electrolyte cell. The combinatorial variation of morphology and high throughput assessment of its influence on product distribution is an important use of this instrument that will be explored in future work. The design requirement to decouple product detection from the electrochemical reactor, which ensures the product detection does not influence the product creation, combined with the high flow rate and desire for much faster $\mathrm{CV}$ cycling than traditional $\mathrm{CO}_{2} \mathrm{RR}$ experiments, dictated the performance requirements for the pervaporator. Existing pervaporator designs did not meet detectability limit requirements, prompting our implementation of the molecular sieve chamber to provide the required 100 -fold improvement in detectability limit. Upon achieving the desired experiment speed, data interpretation required simulation of the product separation and detection. Integration of these components into a high throughput instrument with automated sample change results in an analytical electrochemistry technology with unprecedented performance.

\section{Conclusion:}

We present a combinatorial screening instrument for MS detection of $\mathrm{H}_{2}, \mathrm{CH}_{4}$ and $\mathrm{C}_{2} \mathrm{H}_{4}$ in quasireal time during catalyst operation experiments in an electrochemical flow cell. The desire to sweep 
potentials and lower experiment time motivates the use of CV characterization, requiring the establishment of a membrane diffusion modelling to relate the time-varying electrocatalysis products with the resulting MS signals. The selective pumping of water and alcohols in the MS pre-chamber enabled a factor of 100 improvement in detectability limit, which is critical for establishing protocols that can detect $1 \% \mathrm{FE}$ of the desired hydrocarbon products. Measurements using a series $\mathrm{Cu}$ electrocatalysts were performed to evaluate reproducibility, demonstrating consistent characterization of the prime signals of interest and identifying where techniques can be altered to meet different research goals. Integrating this accelerated screening technique with high throughput synthesis and characterization enabled rapid screening of new catalyst compositions and phases in the Pd-Zn system, with screening results indicated activity for $\mathrm{CO}_{2} \mathrm{RR}$ but not to the desired hydrocarbon products. The use of repeated $\mathrm{CV}$ measurements on each catalyst enables characterization of initial transients in catalytic properties while also exploring a large window of overpotential, making this instrument uniquely suited for exploring $\mathrm{CO}_{2} \mathrm{RR}$ electrocatalysts.

\section{Acknowledgements}

This material is based upon work performed by the Joint Center for Artificial Photosynthesis, a DOE Energy Innovation Hub, supported through the Office of Science of the U.S. Department of Energy (Award No. DE-SC0004993). Use of the Stanford Synchrotron Radiation Lightsource, SLAC National Accelerator Laboratory, is supported by the U.S. Department of Energy, Office of Science, Office of Basic Energy Sciences under Contract No. DE-AC02-76SF00515. The authors thank Apurva Mehta and Douglas G. Van Campen for assistance with collection of synchrotron XRD data.

Supporting Information. Evaluation of effect of electrolyte flow rate

\section{References:}

(1) Kumar, B.; Llorente, M.; Froehlich, J.; Dang, T.; Sathrum, A.; Kubiak, C. P. Photochemical and Photoelectrochemical Reduction of $\mathrm{CO}_{2}$. Annual Review of Physical Chemistry 2012, 63 (1), 541-569. https://doi.org/10.1146/annurev-physchem-032511143759.

(2) Nitopi, S.; Bertheussen, E.; Scott, S. B.; Liu, X.; Engstfeld, A. K.; Horch, S.; Seger, B.; Stephens, I. E. L.; Chan, K.; Hahn, C.; et al. Progress and Perspectives of Electrochemical $\mathrm{CO}_{2}$ Reduction on Copper in Aqueous Electrolyte. Chemical Reviews 2019, 119, 76107672. https://doi.org/10.1021/acs.chemrev.8b00705.

(3) Hori, Y.; Wakebe, H.; Tsukamoto, T.; Koga, O. Electrocatalytic Process of CO Selectivity in Electrochemical Reduction of CO2 at Metal Electrodes in Aqueous Media. Electrochimica Acta 1994, 39 (11-12), 1833-1839. https://doi.org/10.1016/00134686(94)85172-7.

(4) Kuhl, K. P.; Cave, E. R.; Abram, D. N.; Jaramillo, T. F. New Insights into the Electrochemical Reduction of Carbon Dioxide on Metallic Copper Surfaces. Energy \& Environmental Science 2012, 5, 7050-7059. https://doi.org/10.1039/c2ee21234j.

(5) McGinn, P. J. Combinatorial Electrochemistry-Processing and Characterization for Materials Discovery. Materials discovery 2015, 1, 38-53.

(6) Jones, R. J. R.; Wang, Y.; Lai, Y.; Shinde, A.; Gregoire, J. M. Reactor Design and Integration with Product Detection to Accelerate Screening of Electrocatalysts for Carbon Dioxide Reduction. Review of Scientific Instruments 2018, 89 (12), 124102. https://doi.org/10.1063/1.5049704.

(7) Grote, J. P.; Zeradjanin, A. R.; Cherevko, S.; Savan, A.; Breitbach, B.; Ludwig, A.; Mayrhofer, K. J. J. Screening of Material Libraries for Electrochemical CO2reduction 
Catalysts - Improving Selectivity of $\mathrm{Cu}$ by Mixing with Co. Journal of Catalysis 2016, 343, 248-256. https://doi.org/10.1016/j.jcat.2016.02.026.

Jambunathan, K.; Hillier, A. C. Measuring Electrocatalytic Activity on a Local Scale with Scanning Differential Electrochemical Mass Spectrometry. Journal of The Electrochemical Society 2003, 150 (6), E312. https://doi.org/10.1149/1.1570823. Jambunathan, K.; Jayaraman, S.; Hillier, A. C. A Multielectrode Electrochemical and Scanning Differential Electrochemical Mass Spectrometry Study of Methanol Oxidation on Electrodeposited Pt x Ru y. Langmuir 2004, 20 (5), 1856-1863.

Baltruschat, H. Differential Electrochemical Mass Spectrometry. Journal of the American Society for Mass Spectrometry 2004, 15 (12), 1693-1706. https://doi.org/10.1016/j.jasms.2004.09.011.

(11) Ashton, S. J. Design, Construction and Research Application of a Differential Electrochemical Mass Spectrometer (DEMS); Springer Science \& Business Media, 2012. Clark, E. L.; Bell, A. T. Direct Observation of the Local Reaction Environment during the Electrochemical Reduction of CO2. Journal of the American Chemical Society 2018, 140 (22), 7012-7020.

(13) Wolter, O.; Heitbaum, J. Differential Electrochemical Mass Spectroscopy (DEMS) —a New Method for the Study of Electrode Processes. Berichte der Bunsengesellschaft für physikalische Chemie 1984, 88 (1), 2-6.

(14) Hartung, T.; Baltruschat, H. Differential Electrochemical Mass Spectrometry Using Smooth Electrodes: Adsorption and H/D-Exchange Reactions of Benzene on Pt. Langmuir 1990, 6 (11), 953-957. https://doi.org/10.1021/la00095a012.

(15) Jusys, Z. A New Approach for Simultaneous DEMS and EQCM: Electro-Oxidation of Adsorbed CO on Pt and Pt-Ru. Journal of The Electrochemical Society 1999, 146 (3), 1093. https://doi.org/10.1149/1.1391726.

(16) Gao, Y.; Tsuji, H.; Hattori, H.; Kita, H. New On-Line Mass Spectrometer System Designed for Platinum-Single Crystal Electrode and Electroreduction of Acetylene. Journal of Electroanalytical Chemistry 1994, 372 (1-2), 195-200. https://doi.org/10.1016/0022-0728(93)03291-V.

(17) Wonders, A. H.; Housmans, T. H. M.; Rosca, V.; Koper, M. T. M. On-Line Mass Spectrometry System for Measurements at Single-Crystal Electrodes in Hanging Meniscus Configuration. Journal of Applied Electrochemistry 2006, 36 (11), 1215-1221. https://doi.org/10.1007/s10800-006-9173-4.

(18) Rus, E. D.; Wang, H.; Legard, A. E.; Ritzert, N. L.; Bruce Van Dover, R.; Abruña, H. D. An Exchangeable-Tip Scanning Probe Instrument for the Analysis of Combinatorial Libraries of Electrocatalysts. Review of Scientific Instruments 2013, 84 (2), 024101. (19) Gregoire, J. M.; Xiang, C.; Liu, X.; Marcin, M.; Jin, J. Scanning Droplet Cell for High Throughput Electrochemical and Photoelectrochemical Measurements. Review of Scientific Instruments 2013, 84 (2), 024102.

(20) Klemm, S. O.; Topalov, A. A.; Laska, C. A.; Mayrhofer, K. J. J. Coupling of a High Throughput Microelectrochemical Cell with Online Multielemental Trace Analysis by ICP-MS. Electrochemistry Communications 2011, 13 (12), 1533-1535. https://doi.org/10.1016/j.elecom.2011.10.017.

(21) Grote, J.-P.; Zeradjanin, A. R.; Cherevko, S.; Mayrhofer, K. J. Coupling of a Scanning Flow Cell with Online Electrochemical Mass Spectrometry for Screening of Reaction Selectivity. Review of Scientific Instruments 2014, 85 (10), 104101. 
(22) Khanipour, P.; Lçffler, M.; Reichert, A. M.; Haase, F. T.; Mayrhofer, K. J. J.; Katsounaros, I. Electrochemical Real-Time Mass Spectrometry (EC-RTMS): Monitoring Electrochemical Reaction Products in Real Time. Angewandte Chemie International Edition 2019, 131 (22), 7273-7277.

(23) Clark, E. L.; Singh, M. R.; Kwon, Y.; Bell, A. T. Differential Electrochemical Mass Spectrometer Cell Design for Online Quantification of Products Produced during Electrochemical Reduction of $\mathrm{CO}<\mathrm{inf}>2</$ Inf $>$. Analytical Chemistry 2015, 87 (15), 8013-8020. https://doi.org/10.1021/acs.analchem.5b02080.

(24) Suram, S. K.; Zhou, L.; Becerra-Stasiewicz, N.; Kan, K.; Jones, R. J.; Kendrick, B. M.; Gregoire, J. M. Combinatorial Thin Film Composition Mapping Using Three Dimensional Deposition Profiles. Review of Scientific Instruments 2015, 86 (3), 033904.

(25) Gregoire, J. M.; Van Campen, D. G.; Miller, C. E.; Jones, R. J. R.; Suram, S. K.; Mehta, A. High-Throughput Synchrotron X-Ray Diffraction for Combinatorial Phase Mapping. Journal of Synchrotron Radiation 2014, 21 (6), 1262-1268. https://doi.org/10.1107/S1600577514016488.

(26) Ohkawa, K.; Noguchi, Y.; Nakayama, S.; Hashimoto, K.; Fujishima, A. Electrochemical Reduction of Carbon Dioxide on Hydrogen-Storing Materials.: Part II. Copper-Modified Palladium Electrode. Journal of Electroanalytical Chemistry 1993, 348 (1-2), 459-464.

(27) Hahn, C.; Abram, D. N.; Hansen, H. A.; Hatsukade, T.; Jackson, A.; Johnson, N. C.; Hellstern, T. R.; Kuhl, K. P.; Cave, E. R.; Feaster, J. T.; et al. Synthesis of Thin Film AuPd Alloys and Their Investigation for Electrocatalytic CO2reduction. Journal of Materials Chemistry A 2015, 3 (40), 20185-20194. https://doi.org/10.1039/c5ta04863j.

(28) Kortlever, R.; Peters, I.; Balemans, C.; Kas, R.; Kwon, Y.; Mul, G.; Koper, M. T. M. Palladium-Gold Catalyst for the Electrochemical Reduction of $\mathrm{CO}_{2}$ to $\mathrm{C}_{1}-\mathrm{C}_{5}$ Hydrocarbons. Chemical Communications 2016, 52 (67), 10229-10232. https://doi.org/10.1039/C6CC03717H.

(29) Bai, X.; Chen, W.; Zhao, C.; Li, S.; Song, Y.; Ge, R.; Wei, W.; Sun, Y. Exclusive Formation of Formic Acid from $\mathrm{CO}_{2}$ Electroreduction by a Tunable Pd-Sn Alloy. Angewandte Chemie International Edition 2017, 56 (40), 12219-12223. https://doi.org/10.1002/anie.201707098.

(30) Furuya, N.; Yamazaki, T.; Shibata, M. High Performance Ru $\square$ Pd Catalysts for CO2 Reduction at Gas-Diffusion Electrodes. Journal of Electroanalytical Chemistry 1997, 431 (1), 39-41. https://doi.org/10.1016/S0022-0728(97)00159-9.

(31) Tao, H.; Sun, X.; Back, S.; Han, Z.; Zhu, Q.; Robertson, A. W.; Ma, T.; Fan, Q.; Han, B.; Jung, Y.; et al. Doping Palladium with Tellurium for the Highly Selective Electrocatalytic Reduction of Aqueous $\mathrm{CO}_{2}$ to CO. Chemical Science 2018, 9 (2), 483-487. https://doi.org/10.1039/C7SC03018E.

(32) Gao, D.; Zhou, H.; Cai, F.; Wang, J.; Wang, G.; Bao, X. Pd-Containing Nanostructures for Electrochemical $\mathrm{CO}_{2}$ Reduction Reaction. ACS Catalysis 2018, 8 (2), 1510-1519. https://doi.org/10.1021/acscatal.7b03612.

(33) Rosen, J.; Hutchings, G. S.; Lu, Q.; Forest, R. V.; Moore, A.; Jiao, F. Electrodeposited Zn Dendrites with Enhanced CO Selectivity for Electrocatalytic $\mathrm{CO}_{2}$ Reduction. ACS Catalysis 2015, 5 (8), 4586-4591. https://doi.org/10.1021/acscatal.5b00922.

(34) Tran, K.; Ulissi, Z. W. Active Learning across Intermetallics to Guide Discovery of Electrocatalysts for CO2 Reduction and H2 Evolution. Nature Catalysis 2018, 1 (9), 696703. https://doi.org/10.1038/s41929-018-0142-1. 


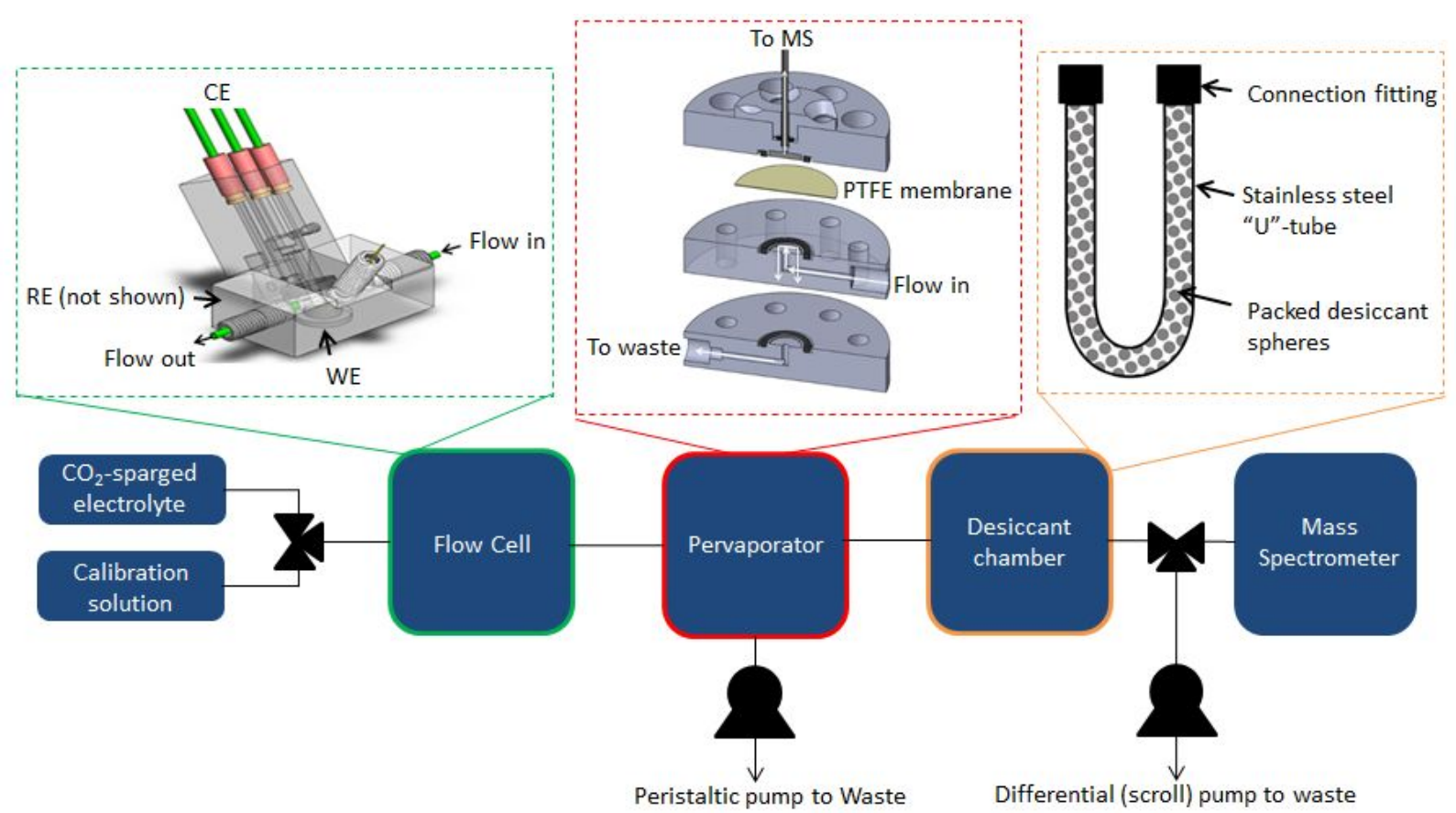

Figure 1. Schematic of the electrochemical flow cell with online product detection. Electrolyte (during catalyst screening) or calibration solution (during MS calibration) is pulled by the peristaltic pump through the electrochemical flow cell where it passes over the working electrode (WE). The reference electrode (RE) is in the working electrode chamber, which is separated from the counter electrode (CE) by a bipolar membrane. The effluent of the electrochemical cell passes through the pervaporation cell, yielding a gaseous flux that flows over a desiccant to selectively pump water vapor and then continues to the MS detection system.

Table 1. Modeling parameters and values (where applicable) for simulating the generation, transport and detection of electrocatalysis reaction products.

\begin{tabular}{|c|c|c|}
\hline Variable & Description & Value or unit \\
\hline \multicolumn{3}{|c|}{ Product creation, transport and detection } \\
\hline $\mathrm{C}_{\mathrm{M}}$ & Mole concentration of a molecule in electrolyte & $\mathrm{mol} / \mathrm{m}^{3}$ \\
\hline$X_{\text {mem }}$ & Effective thickness of membrane & $610^{-4} \mathrm{~m}$ \\
\hline $\mathrm{x}$ & $\begin{array}{l}\text { Position along membrane thickness that is } 0 \text { at flowing } \\
\text { electrolyte interface and } X_{\text {mem }} \text { at vacuum interface }\end{array}$ & $\mathrm{m}$ \\
\hline$\delta_{\mathrm{x}}$ & Differential distance step used in simulation & $110^{-5} \mathrm{~m}$ \\
\hline $\mathrm{t}$ & Time from the start of the CV measurement & s \\
\hline$\delta_{\mathrm{t}}$ & Differential time step used in simulation & $110^{-3} \mathrm{~s}$ \\
\hline $\mathrm{d}_{\mathrm{mem}}$ & Electrolyte diffusion layer thickness at membrane interface & $110^{-6} \mathrm{~m}$ \\
\hline$\rho$ & $\begin{array}{l}\text { Pervaporation rate for volatile species, i.e. partial pressure of } \\
\text { a species per molecular concentration at the membrane- } \\
\text { vacuum interface }\end{array}$ & $\begin{array}{l}3.7210^{-6} \\
\text { torr* } \mathrm{m}^{3} / \mathrm{mol}\end{array}$ \\
\hline
\end{tabular}




\begin{tabular}{|c|c|c|}
\hline$(\mathrm{m} / \mathrm{z})_{\mathrm{M}}$ & $\begin{array}{l}\text { Mass to charge ratio for mass spectrometer (MS) } \\
\text { measurement of each molecule }\end{array}$ & $\begin{array}{l}\mathrm{H}_{2}: 2 \\
\mathrm{CH}_{4}: 15 \\
\mathrm{C}_{2} \mathrm{H}_{4}: 26\end{array}$ \\
\hline $\mathrm{S}_{\mathrm{M}}$ & $\begin{array}{l}\text { Relative sensitivity of each gas molecule in MS at the } \\
\text { respective } \mathrm{m} / \mathrm{z} \text { value, calibrated approximately once per day }\end{array}$ & $\begin{array}{l}\mathrm{H}_{2}: \sim 3.8 \\
\mathrm{CH}_{4}: \sim 1.6 \\
\mathrm{C}_{2} \mathrm{H}_{4}: \sim 0.75\end{array}$ \\
\hline $\mathrm{D}_{\mathrm{M}}$ & Gas diffusion coefficient in electrolyte & $\begin{array}{l}\mathrm{H}_{2}: 2.210^{-9} \mathrm{~m}^{2} / \mathrm{s} \\
\mathrm{CH}_{4}: 1.810^{-9} \mathrm{~m}^{2} / \mathrm{s} \\
\mathrm{C}_{2} \mathrm{H}_{4}: 1.810^{-9} \\
\mathrm{~m}^{2} / \mathrm{s}\end{array}$ \\
\hline $\mathrm{P}_{\mathrm{M}}$ & Detected partial pressure by MS & torr \\
\hline$t_{i, M}$ & Time point where a MS measurement is made & $\mathrm{s}$ \\
\hline $\mathrm{P}_{\text {meas }, \mathrm{M}}$ & Measured value of $\mathrm{P}_{\mathrm{M}}$ as a function of time & torr \\
\hline $\mathrm{FE}_{\mathrm{M}}$ & Faradaic Efficiency for a given product & Fraction \\
\hline $\mathrm{f}$ & Flow rate of electrolyte & $\mathrm{mL} / \mathrm{s}$ \\
\hline $\mathrm{n}_{\mathrm{M}}$ & Number of e- per mole of product from $\mathrm{CO}_{2} \mathrm{RR}$ & $1 / \mathrm{mol}$ \\
\hline$\Gamma_{M}$ & flow rate of gas molecules after the membrane & $\mathrm{mol} / \mathrm{s}$ \\
\hline $\mathrm{F}$ & Faraday constant & $96485 \mathrm{~s} \mathrm{~A} / \mathrm{mol}$ \\
\hline \multicolumn{3}{|c|}{ CV scan modeling } \\
\hline $\mathrm{E}$ & Electrochemical potential & V vs RHE \\
\hline$E_{1}$ & Turn-around potential, i.e. minimum potential of CV & $-1.3 \mathrm{~V}$ vs. RHE \\
\hline$t_{0}, t_{2}$ & Start and stop times of the CV & $0 \mathrm{~s}, 180 \mathrm{~s}$ \\
\hline $\mathrm{J}_{\mathrm{p}, \mathrm{M}}$ & Partial current density for a given product & $\mathrm{mA} / \mathrm{cm}^{2}$ \\
\hline $\mathrm{J}_{1, \mathrm{M}}$ & Partial current density for a given product at $\mathrm{E}_{1}$ & $\mathrm{~mA} / \mathrm{cm}^{2}$ \\
\hline$\mu_{\mathrm{M}}$ & Value of $\mathrm{E}$ where $\mathrm{J}_{\mathrm{p}, \mathrm{M}}$ is maximal in Gaussian model & V vs. RHE \\
\hline $\mathrm{P}_{\text {model, } \mathrm{M}}$ & Modelled value of $\mathrm{P}_{\mathrm{M}}$ as a function of time & torr \\
\hline$\sigma_{\mathrm{M}}$ & Width of $\mathrm{J}_{\mathrm{p}, \mathrm{M}}(\mathrm{E})$ peak in Gaussian model & $\mathrm{V}$ \\
\hline $\mathrm{L}_{\mathrm{M}}$ & Total loss of $\mathrm{P}_{\text {model, } \mathrm{M}}$ with respect to $\mathrm{P}_{\text {meas }, \mathrm{M}}$ for a single $\mathrm{CV}$ & torr $^{2}$ \\
\hline
\end{tabular}




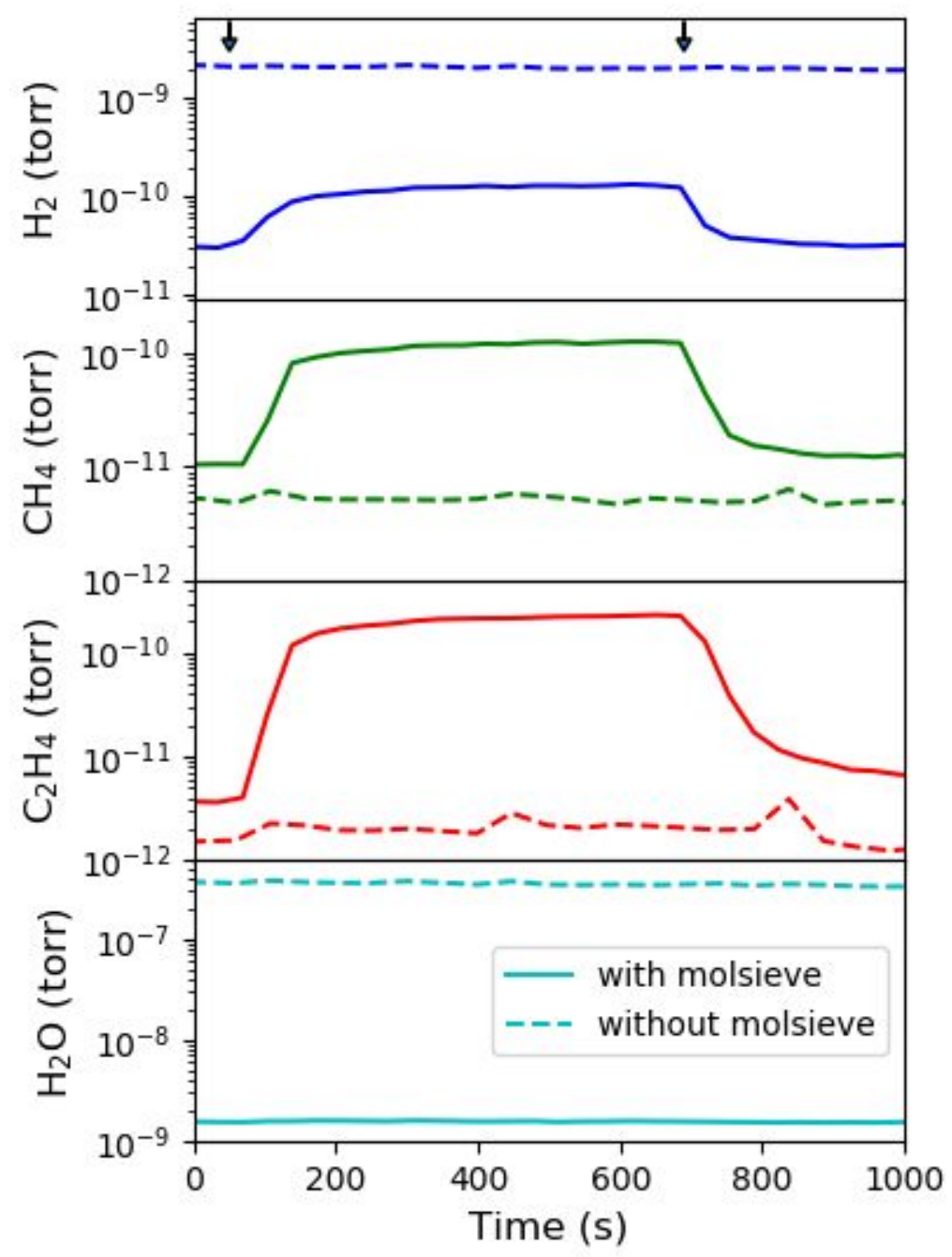

Figure 2. MS signal comparing the use and absence of molecular sieve in the EC-MS system. The comparison was made by controlling the total MS pressure to be $\sim 1.5 \mu$ Torr for each test. The first arrow on the left indicates when the flowing electrolyte was switched from $\mathrm{CO}_{2}$ bubbled one to calibration gas-bubbled one, while the arrow on the right indicates a reversed switch. The calibration gas used for bubbling electrolyte contains $1 \% \mathrm{H}_{2}, 1 \% \mathrm{CH}_{4}$, and $1 \% \mathrm{C}_{2} \mathrm{H}_{4}$ balanced with $\mathrm{CO}_{2}$. 

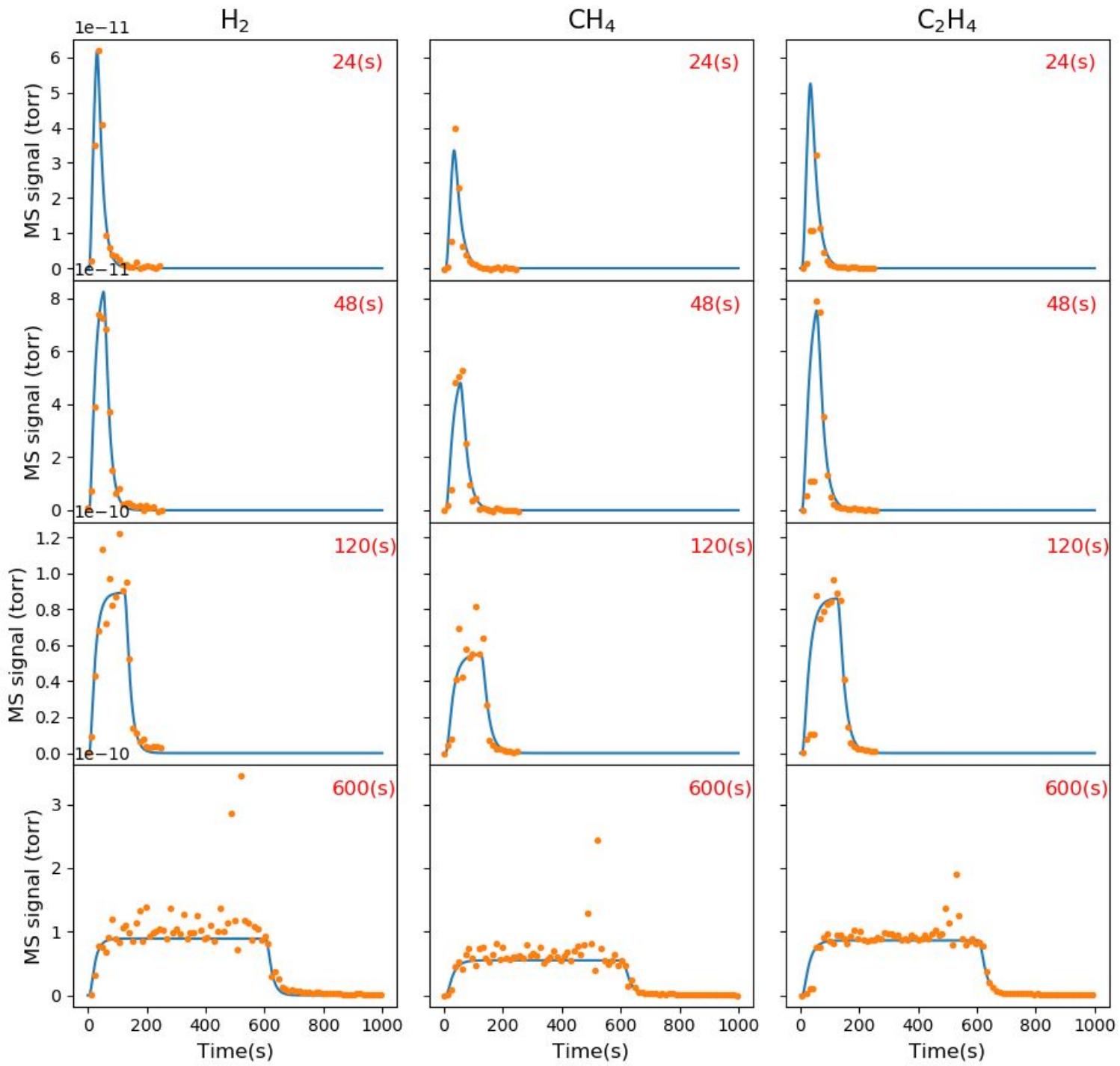

Figure 3. Modeled MS signals ( $\mathrm{P}_{\mathrm{M}}$, solid line) vs MS experimental data (dotted line) from a calibration gas solution pulsed at different time durations. 
a.
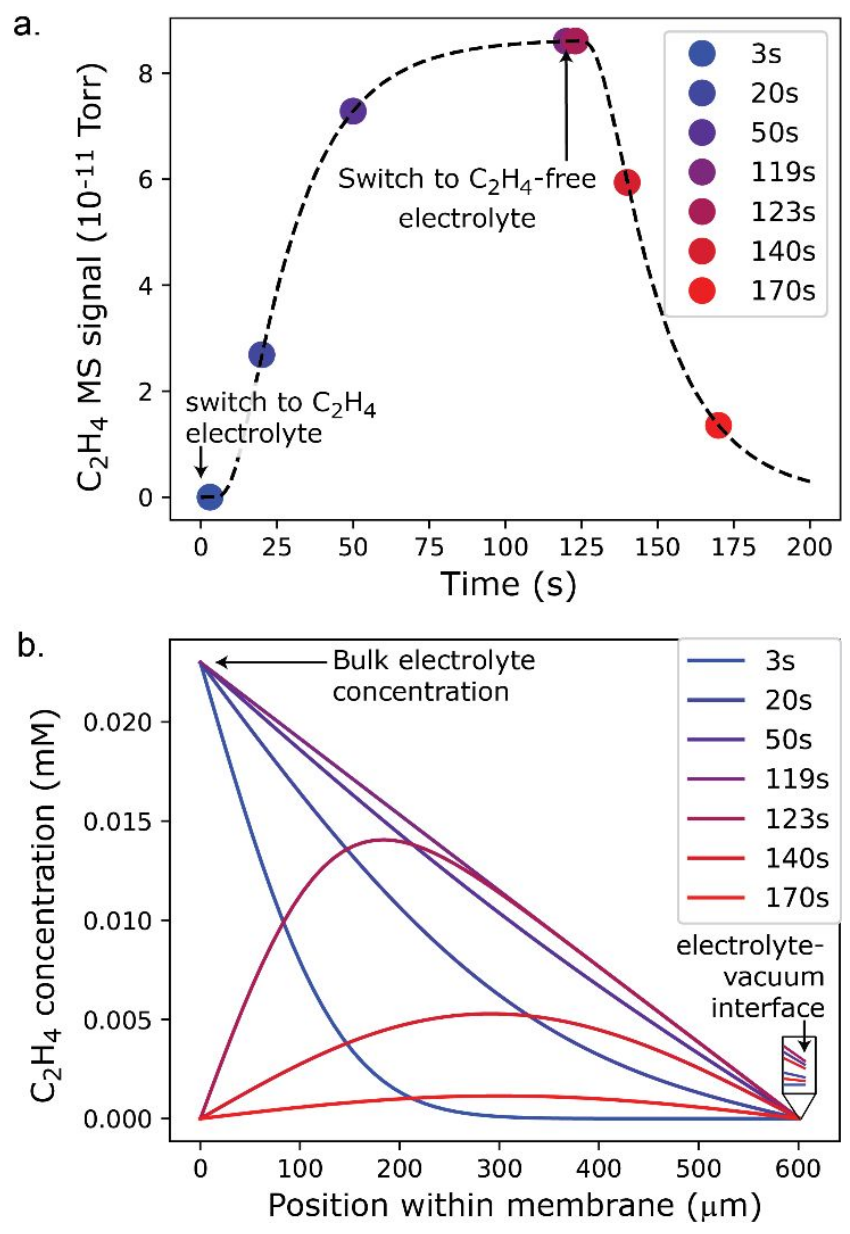

Figure 4. Example simulation results for flowing electrolyte containing no $\mathrm{C}_{2} \mathrm{H}_{4}$, then $0.023 \mathrm{mM}$ $\mathrm{C}_{2} \mathrm{H}_{4}$ from 0 to $120 \mathrm{~s}$, then no $\mathrm{C}_{2} \mathrm{H}_{4}$. a) The simulated MS signals and b) the correspondingly $\mathrm{C}_{2} \mathrm{H}_{4}$ concentration within the PTFE membrane. 

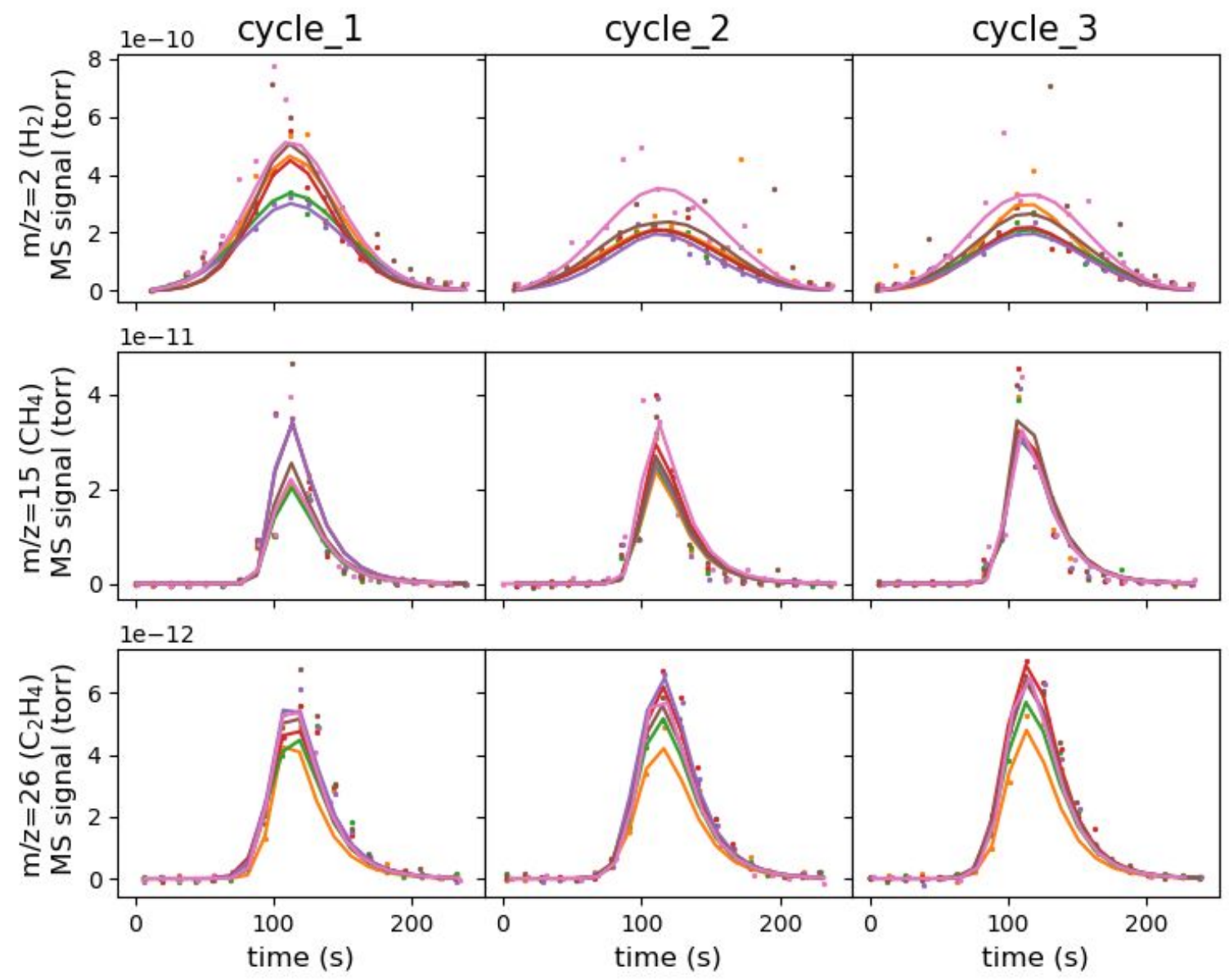

Figure 5. Raw (dotted line) and fitted MS signal (solid line) for 3CVs scanned sequentially over $6 \mathrm{Cu}$ thin film electrodes. 

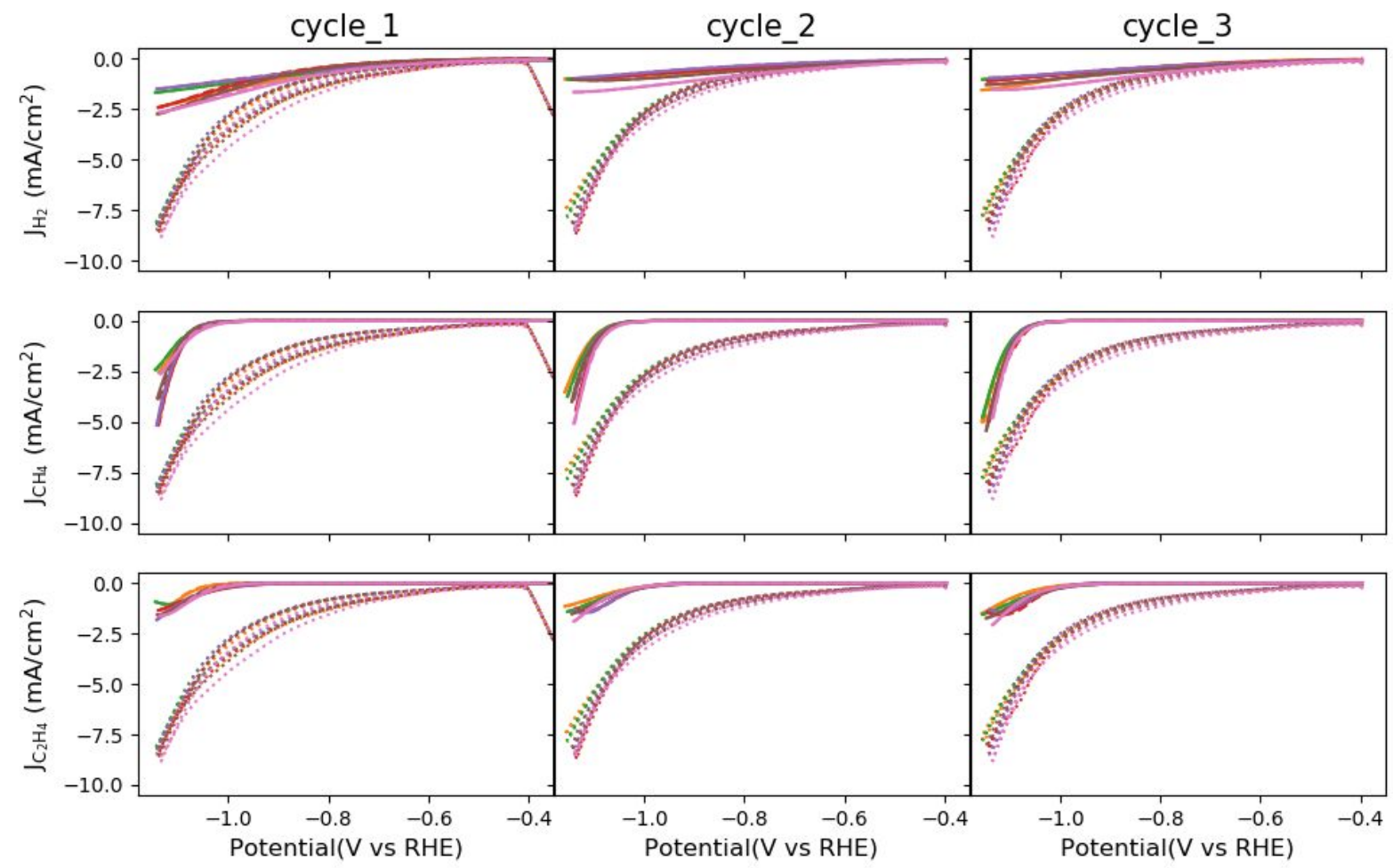

Figure 6. Smoothed $\mathrm{J}_{\text {total }}$ (dotted line, same data for each product) and modeled $\mathrm{J}_{\mathrm{p}}$ (solid line for cathodic sweep and dashed line for anodic sweep, although strong overlap with cathodic sweep makes anodic and cathodic indistinguishable) for $3 \mathrm{CVs}$ scanned sequentially over $6 \mathrm{Cu}$ thin film electrodes. 

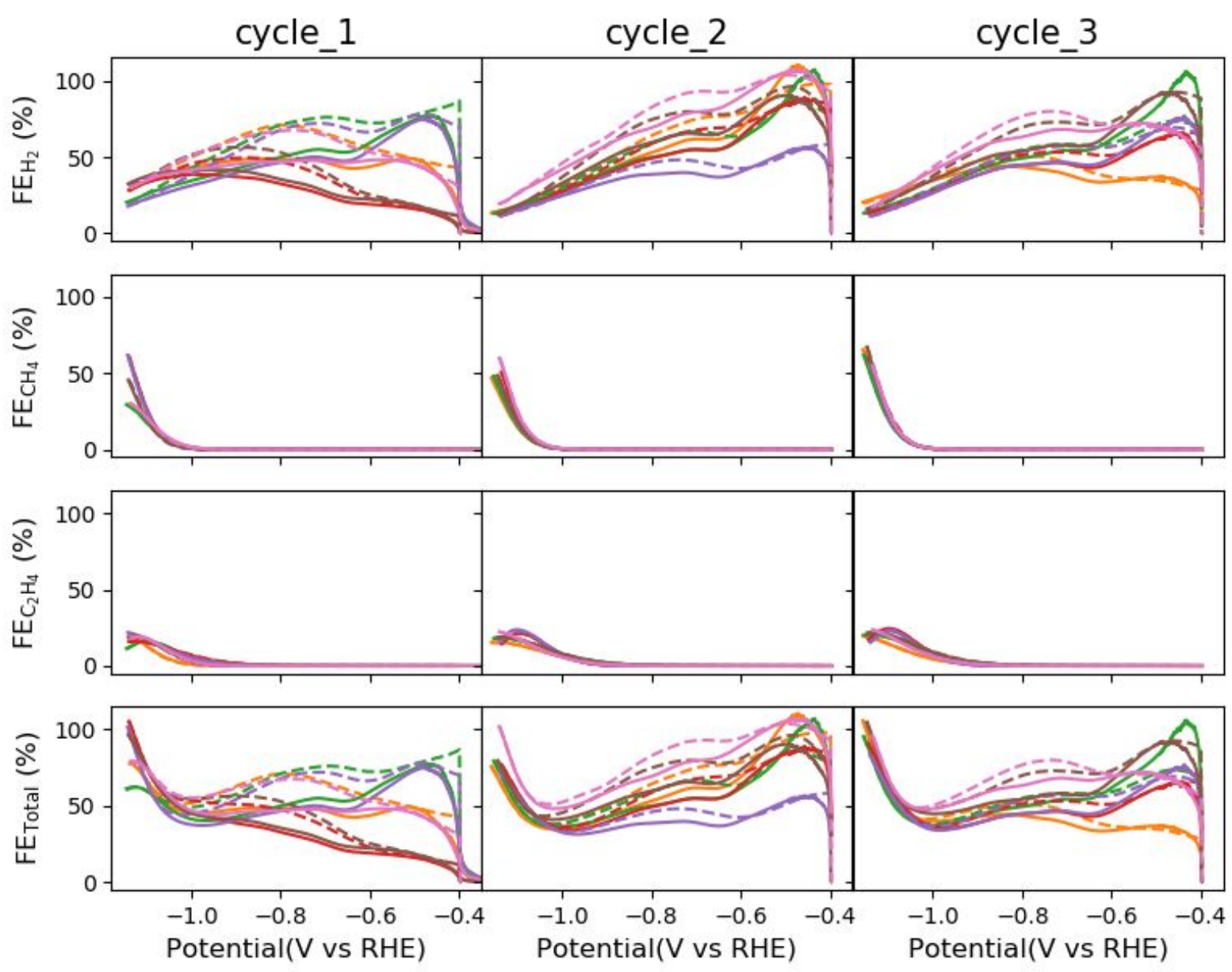

Figure 7. FE (solid line for cathodic sweep and dashed line for anodic sweep) for $3 \mathrm{CVs}$ scanned sequentially over $6 \mathrm{Cu}$ thin film electrodes. The modelling results are largely determined by the high partial current density region for each product, making the $\mathrm{H}_{2}$ results well reproduced below $-0.8 \mathrm{~V}$ vs RHE but less so at higher potentials. 

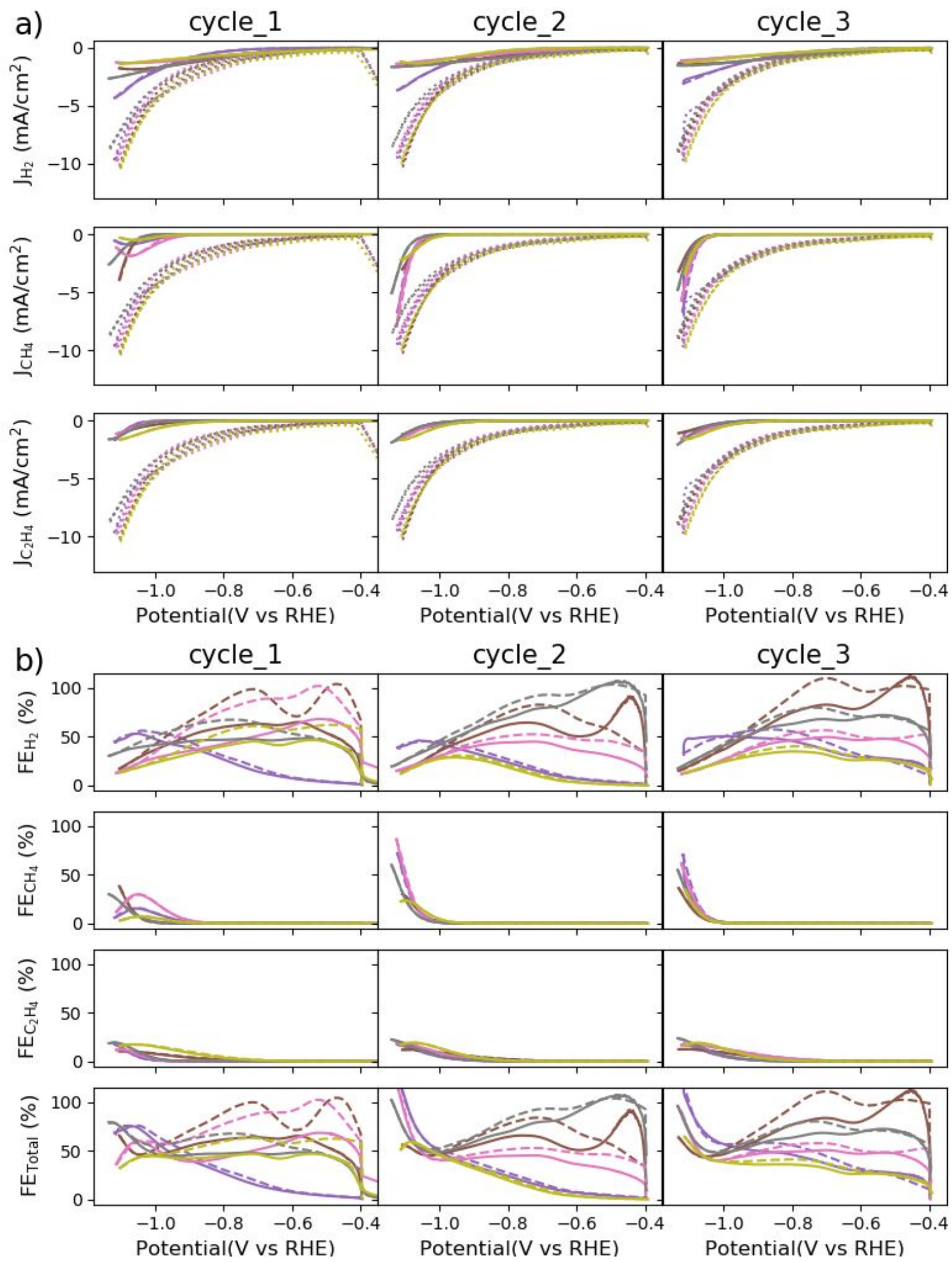

Figure 8. a) Smoothed $\mathrm{J}_{\text {total }}$ (dotted line) and modeled $\mathrm{J}_{\mathrm{p}}$ (solid line for cathodic sweep and dashed line for anodic sweep), and b) FE (solid line for cathodic sweep and dashed line for anodic sweep) for $3 \mathrm{CVs}$ acquired on 6 different $\mathrm{Cu}$ thin film electrodes each measured on a different day spanning 4 months. The 
modelling results are largely determined by the high partial current density region for each product, making the $\mathrm{H}_{2}$ results well reproduced below $-0.8 \mathrm{~V}$ vs RHE but less so at higher potentials.

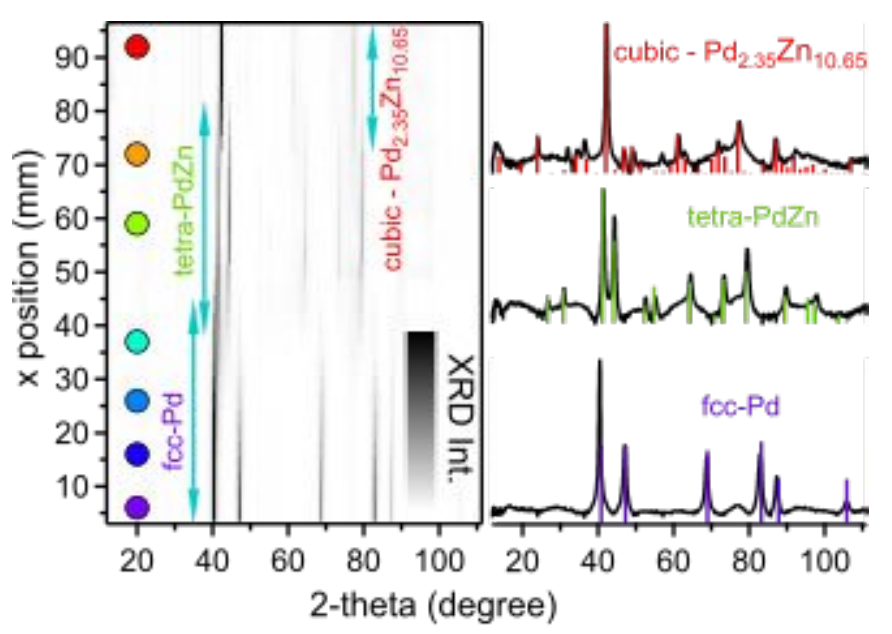

Figure 9. XRD characterization of the Pd-Zn composition library revealing the presence of 2 binary intermetallic phases in addition to the fcc Pd phase, as well as alloying within each phase. The heat map (left) shows the measured XRD intensity along the compositionally graded thin film from Pd-rich (bottom) to Zn-rich (top), with the colored circles corresponding to the positions of the series of 7 electrocatalyst samples. The comparison of select XRD patterns to entries in the ICDD (right) provide the phase labels that appear on the heatmap. 


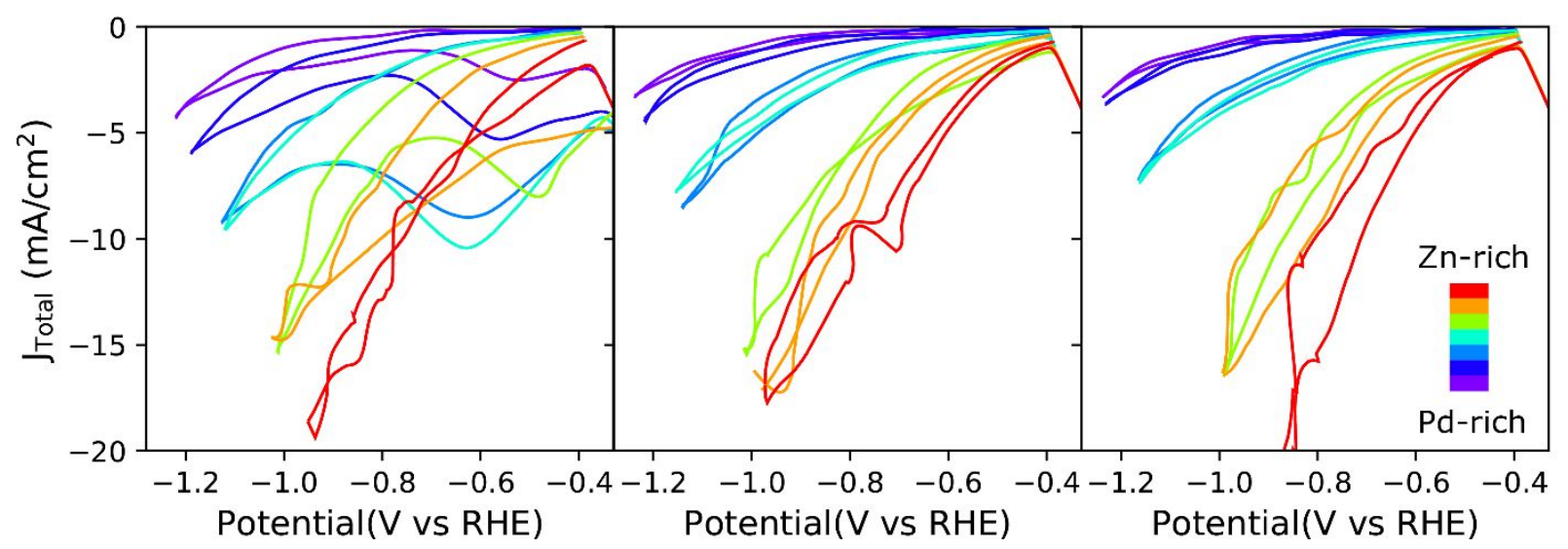

Figure 10. Measured electrocatalyst current and $\mathrm{FE}$ for $\mathrm{H}_{2}$ for $3 \mathrm{CVs}$ scanned sequentially over a series of $7 \mathrm{Pd}-\mathrm{Zn}$ thin film electrocatalysts. The $\mathrm{CH}_{4}$ and $\mathrm{C}_{2} \mathrm{H}_{4}$ are not shown as these products were not detected. The color designates composition from Pd-rich to Zn-rich sample spots and matches that of Fig. 9. Each solid (dashed) line is a cathodic (anodic) sweep with the only substantial variation in FE with sweep direction where lower FE on the initial cathodic sweep of only the first CV indicates initial reduction of oxides from air exposure, which is most pronounced for the samples with the PdZn phase. 
For Table of Contents Use Only

Scanning electrochemical flow cell with online mass spectroscopy for accelerated screening of carbon dioxide reduction electrocatalysts

Yungchieh Lai ${ }^{1}$, Ryan J.R. Jones ${ }^{1}$, Yu Wang ${ }^{1}$, Lan Zhou ${ }^{1}$, and John M. Gregoire, ${ }^{1, *}$
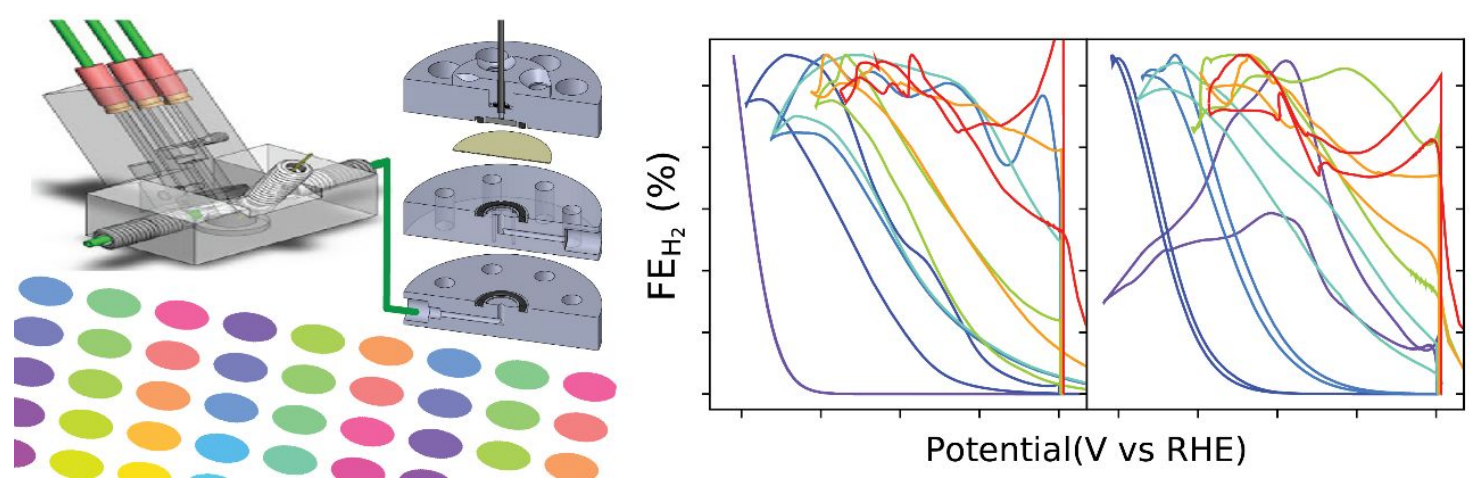